\title{
El Madrid que mira hacia la Meca. La producción simbólica de alternativas sociales ${ }^{1}$
}

\author{
MARGARITA DEL OLMO PINTADO \\ Dpto. Antropología de España y América \\ CSIC, Madrid
}

En el marco de un estudio sobre la etnohistoria de Madrid, el presente trabajo tiene la intención de contribuir a un análisis de la complejidad social de la ciudad en la época contemporánea; pero trata de acometer una tarea tan ambiciosa utilizando como herramienta un ejemplo muy concreto. De esta manera, mi objetivo fundamental será explorar las posibilidades de un grupo de musulmanes que vive actualmente en la ciudad a la hora de negociar un espacio simbólico en la sociedad madrileña, y las alternativas sociales que se derivan de esa negociación para el resto de sus habitantes.

Tengo interés en prestar una atención especial al análisis de las fronteras de ese espacio, tal y como se formulan y se manipulan desde dentro y desde fuera; pero abandonando, por completo, la intención de ser exhaustiva y ofreciendo, conscientemente, una perspectiva fragmentaria en la que el lector pueda incluir, sin ningún problema, su propia experiencia.

Voy a presentar mi argumentación dividida en tres partes. A lo largo de la primera trataré de enmarcar la discusión en un contexto teórico más amplio, elaborando algunos de los elementos que considero más importantes a la hora de plantear un análisis sobre la dinámica social en sociedades complejas contemporáneas. La segunda estará dedicada a tratar el material recogido que considero relevante para llevar a cabo mi argumentación. La tercera tendrá como objetivo explorar cuáles son los ángulos de la dinámica social de la ciudad de Madrid que ilumina el análisis de un ejemplo tan concreto como el propuesto.

\footnotetext{
${ }^{1}$ El análisis que aquí presento es fruto de una investigación en curso que, con el título de "Los conversos españoles al Islam", se inscribe dentro del proyecto de investigación "Análisis antropológico de las manifestaciones de culto a santo y vírgenes en Madrid" dirigido por Matilde Fernández (PB1997-1182). Deseo expresar mi agradecimiento, tanto a la directora del proyecto por las críticas a la primera versión del artículo, como a Noria Attou y a Radja Zedazi por la generosa ayuda que me han prestado.
} 


\section{LA DINÁMICA SOCIAL DESDE LA PRODUCCIÓN SIMBÓLICA DE LA MODERNIDAD}

A la hora de aceptar un desafío como el de analizar la dinámica social en las complejas ciudades de nuestro mundo contemporáneo, así como de los procesos que están implicados en ella, los científicos sociales han ido abandonando, progresivamente, la pretensión de ser objetivos. Por fortuna esta renuncia ha dado muchos frutos; entre ellos me parecen significativos dos muy recientes: la necesidad de considerar la investigación de forma fragmentaria, esto es, no representativa o, con mayor propiedad, parcialmente representativa, por un lado, con independencia de cuál sea su posición social concreta en la estructura, incluyendo la del propio investigador, por otro. Ambas direcciones han permitido incluir como objeto de investigación algunos materiales que anteriormente eran desechados y a la vez no sólo apreciar, sino subrayar, la riqueza de la diversidad.

Desde esta perspectiva es fácil terminar en el nihilismo o en el caos, pero también es posible replantear muchas cosas sin caer ni en lo uno ni en lo otro, y entre ellas acometer, desde una nueva perspectiva, el análisis de la estructura social de las ciudades en las sociedades complejas. No es necesario abarcar por completo una ciudad, ni desde un punto de vista estadístico, ni al estilo de las antiguas monografías antropológicas en las que el investigador tenía que ser capaz, o al menos tener la ilusión de serlo, de aprehender el universo simbólico de su comunidad, para reclamar hoy la legitimidad de plantear una pregunta, o analizar una experiencia, un acontecimiento, un lugar; pero sí se requiere ser consciente de que de esta manera sólo es posible ofrecer un reflejo fragmentario y metafórico de eso que llamamos ciudad. Las posibilidades de esa metáfora no acaban, sin embargo, en la capacidad imaginativa del investigador, sino que se hacen conscientes y públicas para entablar un diálogo con la imaginación del que le escucha o le lee.

Empleando este enfoque una ciudad es, fundamentalmente, heterogénea, y por lo tanto una de las formas de analizarla es explorar su heterogeneidad. No se trata de dar un sentido a sus diferencias, sino de entender cuáles son los espacios sociales que esas diferencias abren, cuáles son las posibilidades con las que cuentan sus habitantes, qué alternativas les ofrecen y cuáles son las condiciones a la hora de plantearse una elección. Se podría igualmente expresar a través de una pregunta como la siguiente: ¿cuáles son los espacios sociales que generan las alternativas simbólicas? A lo largo de este trabajo voy a tratar de contestarla desde el ejemplo sugerido, de manera que mi planteamiento se concretaría así: ¿qué alternativas sociales produce en la ciudad de Madrid la existencia de una comunidad musulmana? 
Antes de comenzar un análisis más concreto me parece necesario hacer referencia a otra cuestión teórica, a la que en términos generales podríamos referirnos como "el debate sobre la modernidad". La modernidad es un concepto viejo y resbaladizo, que se ha analizado desde muchas perspectivas y de maneras muy diferentes. No es mi intención aquí sumarizar esta polémica, ni siquiera a grandes rasgos, sino recoger algunas de las ideas que me han resultado más útiles.

Algunos antropólogos al hablar de modernidad han intentado definir qué es lo que caracteriza la época en la que vivimos. En este sentido, resulta especialmente sugerente la argumentación de Arjun Appadurai. En su opinión (Appadurai 1995: 191-210, y 1998), el rasgo más significativo de la sociedad contemporánea es la enorme posibilidad, a disposición del individuo, de imaginarse viviendo estilos de vidas distintos; él cree que ello es debido a dos factores determinantes: la accesibilidad y la rapidez de los medios de transporte que nos permiten trasladarnos a una escala y con una velocidad impensable hace sólo algunos años, y los medios de comunicación de masas que alcanzan audiencias remotas y consiguen hacer próximas y cotidianas unas imágenes que pueden estar produciéndose en el otro extremo del globo.

Considero muy fructífero este planteamiento a la hora de analizar las ciudades contemporáneas, especialmente al ponerlas en relación con mi argumentación anterior. Desde esta perspectiva nuestras sociedades, en tanto que participan de este fenómeno que hemos decidido llamar "modernidad", deberían hacer posible este acceso a estilos de vida diferentes y reflejarlo, de alguna forma, en sus estructuras.

Creo que la emigración, es decir el movimiento de personas que han crecido en una sociedad determinada y que se han trasladado a vivir en otra, es un fenómeno particularmente adecuado para analizar este tipo de procesos sociales. En primer lugar porque estas mismas personas son factores de modernización al poner en contacto dos comunidades distantes, haciendo cotidianas algunas imágenes que en el imaginario colectivo, tanto en la sociedad de origen como en la receptora, pertenecían hasta ese momento a la categoría de "exótico", y por lo tanto se consideraban lejanas e inaccesibles. En segundo porque su integración en la nueva estructura social pone a prueba los mecanismos de ésta para acoger las diferencias, desafiando los modos de pensar tradicionales. $\mathrm{Y}$ en tercero porque están provocando un cambio, por mínimo que sea.

El ejemplo que propongo me permite plantear este mismo problema de una manera mucho más concreta: en una ciudad como Madrid, donde la presencia de un grupo de personas que practican el Islam es un hecho relativamente nuevo (al menos en el periodo contemporáneo) y que 
se ha derivado, fundamental aunque no exclusivamente, de la inmigración, ser musulmán ise ha convertido en una alternativa desde el punto de vista social?, ¿cuál es el espacio que ha generado la estructura para este estilo de vida sea viable?

\section{EL MADRID QUE ESTÁ MIRANDO HACIA LA MECA}

La comunidad musulmana que vive actualmente en Madrid está integrada, en su mayoría por inmigrantes extranjeros (entre los cuales se pueden distinguir tres categorías: naturalizados, extranjeros con permiso de residencia e ilegales), por sus hijos nacidos en España y además por los españoles que se han convertido al Islam.

Es imposible saber cuántos musulmanes residen actualmente en Madrid. Los censos periódicos de población que se realizan en el país no contienen información sobre la adscripción religiosa, aunque sí ofrecen datos sobre la procedencia de los inmigrantes extranjeros. De manera que, teniendo en cuenta el número de personas que proceden de países musulmanes o de mayoría musulmana, se realizan estimaciones que incluyen un cómputo de los inmigrantes extranjeros con permiso de residencia y el colectivo de los inmigrantes ilegales (realizados especialmente a partir de los procesos de regularización) ${ }^{2}$.

La magnitud del grupo de los conversos es imposible de determinar, ya que, como ya he mencionado, la adscripción religiosa no se consigna en los censos del país y, según el derecho islámico, la decisión de adoptar el Islam es un acto de carácter privado, que sólo se hace público si el converso así lo desea, y a cuya petición la mezquita puede elaborar un documento que lo ratifique ${ }^{3}$.

Por otra parte es necesario tener en cuenta que el estado español ha reconocido jurídicamente, desde la Constitución de 1978, la alibertad religiosa" como "un principio fundamental de la convivencia", y el 10 de noviembre de 1992 el Rey de España ratificó un acuerdo específico entre el Estado y la Comisión Islámica de España, donde se sentaron las bases jurídicas para la relación con el colectivo musulmán y se reconoció el Islam como una religión de "notorio arraigo" en nuestro país ${ }^{4}$.

\footnotetext{
2 Véanse al respecto, especialmente, los trabajos de Antonio Izquierdo (1992 y 1996).

${ }^{3}$ Hago esta afirmación sobre la base de la opinión del imán del Centro Cultural Islámico, conocido popularmente como la Mezquita de la M-30.

${ }^{4}$ Amérigo Cuervo-Arango (1995:155-164) y Tatary Bakry (1995:165-172) analizan por extenso, tanto el marco jurídico español, como el acuerdo concreto subscrito.
} 
La expresión "notorio arraigo" hace referencia no sólo al hecho de que se halle establecida en España una comunidad de cierta entidad, sino a la importancia de la religión a lo largo de la historia del país. Esta huella histórica se manifiesta, tanto a través de vestigios histórico-arqueológicos ${ }^{5}$, como en la memoria colectiva de sus habitantes, que se nutre de la constante reinterpretación histórica y que está relacionada con la imagen con la que se representa el grupo ${ }^{6}$. El proceso de reinterpretación histórica es especialmente importante para el caso que nos ocupa, puesto que interviene en la formación de la memoria colectiva, y de esa manera pasa a formar parte del material simbólico que se utiliza en la negociación actual del espacio social. Es necesario reconocer y subrayar este proceso concreto, ya que lo singulariza con respecto a la creación de otras dinámicas sociales en las que no esté implicado el pasado de manera tan directa. Con esto quiero decir que los musulmanes que viven en Madrid, por novedosa que resulte su presencia en estos momentos, están evocando de forma muy particular unas determinadas imágenes históricas, ya que España se construyó ideológicamente como estado a partir de la exclusión religiosa en general, y de judíos y musulmanes en particular, posteriormente, a pesar de todo, reinterpretada ${ }^{7}$.

La producción simbólica se hace eco de todo este proceso y lo hace intervenir, de forma consciente e inconsciente a la vez, a la hora de negociar esta determinada alternativa en el espacio social de un grupo de personas que viven hoy en Madrid con el deseo, y el precepto, siempre que las circunstancias lo permitan, de orientarse hacia la Meca para rezar cinco veces al día. Estas personas tienen muchas otras necesidades que satisfacer, muchas de ellas coinciden con las del resto de la población que vive en la ciudad, pero otras son singulares por derivarse directamente de las normas religiosas a las que se comprometieron cuando abrazaron el Islam.

España no es un país musulmán y no ha contado con una presencia significativa de musulmanes en los últimos tiempos, sin embargo al reconocer jurídicamente el derecho a la presencia de esta religión, se ha obligado a hacer posible su práctica en el territorio nacional; este com-

\footnotetext{
${ }^{5}$ Para un análisis de los mismos remito al artículo de Manuela Marín que se incluye en este volumen, así como a las referencias bibliográficas que cita.

${ }^{6}$ Un excelente resumen a este respecto se puede encontrar en García-Arenal (2000: IX-XIII).

${ }^{7}$ Quiero destacar ahora la importancia de esta argumentación porque, ni el espacio de que dispongo, ni el material recogido, me van a permitir elaborar estas ideas más ampliamente por el momento; sin embargo, Eduardo Manzano lo ha tratado extensamente (2000:33-62).
} 
promiso otorga a la Comunidad Islámica de España el derecho a reclamar los cambios y las excepciones que sean necesarias a la hora de aplicar tanto las normas como las costumbres. Sin embargo, en última instancia, la responsabilidad de que sea o no posible vivir como musulmán en España recae sobre el tejido social, de manera que la posibilidad de seguir estos estilos de vida, inexistentes anteriormente, tiene que crearse a partir de una "negociación" social entre los intereses de unos y otros, y las costumbres de todos.

Para tratar de comenzar por el principo, voy a reproducir algunos fragmentos de los discursos que he obtenido en mi trabajo de campo. A través de ellos pretendo reflejar la percepción del espacio musulmán, tanto entre musulmanes como entre los que no lo son. A este respecto, una mujer que practica el Islam me decía en una conversación:

Espacios musulmanes no hay muchos aquí en Madrid. Solamente la Mezquita como un lugar así, pero vamos... [...] No hay espacios así, ¿no?, de musulmanes. La Mezquita...8

Es evidente que esta persona percibe el espacio como limitado, y más adelante elabora este aspecto más extensamente:

Otra cosa es que..., hay personas que, que, que dentro de sus casas, eh..., por ejemplo, un sábado o un domingo hacen [una] reunión, ¿sabes?, entre ellos. Y eso es más importante, ¿sabes?. Por ejemplo, es que a veces hay personas que no pueden..., por ejemplo, no sé, [a] causa de trabajar..., ino sé!, ¡cualquier cosa!, que no pueden venir a [la] Mezquita y... Por ejemplo, trabajan en la hora de [la] oración del viernes, por ejemplo, pues no [se] pueden juntar con..., otras personas, entonces ellos hacen un[a] reunión así en sus casas el..., el..., bueno el sábado, o el domingo, y hacen así [una] reunión, y hablan sobre el Islam. Y..., y yo participaba, ¡bueno!, es que conozco a..., a mucha gente que está haciendo eso... Como no tienen otro espacio, entonces prefieren hacerlo en sus casas, ¿sabes?, y hacen luego comidas y rezan juntos, ¿sabes? Y la mayoría de ellos son españoles... No sé por qué.

Este testimonio permite darnos cuenta de una estrategia de adaptación que consiste en compartir el espacio privado para suplir la falta de espacio público. A este ámbito en las fronteras entre lo público y lo privado, pertenece toda una serie de pisos que funcionan como mezquitas (especialmente en la zona de Lavapiés), donde la gente se reune a

${ }^{8}$ Tanto este testimonio como el resto de los que se citan a lo largo del artículo proceden de las entrevistas realizadas entre 1999 y 2000 entre musulmanes conversos y no conversos, familiares de conversos y residentes en Madrid no musulmanes. Este trabajo, como la investigación en la que se inscribe, se encuentra actualmente en curso. 
rezar, a compartir sus conocimientos religiosos o sus experiencias cotidianas. Además de estas mezquitas, que han aumentado de forma espectacular a lo largo de los últimos años, existen en Madrid otras dos, digámoslo así, "oficiales", una en el barrio de Estrecho-Cuatro Caminos, y otra a uno de los lados de la M-30. Así me lo expresó una informante:

Los lugares más importantes para los musulmanes [son] la Mezquita de [la] M$30 \ldots$, la más grande, [y] luego la de Estrecho... Pues ya nada más.

Entre ellas, la más conocida, tanto para musulmanes como para los que no lo son es la que se denomina de manera popular "Mezquita de la M-30, cuyo nombre oficial es "Centro Cultural Islámico". La mezquita de Estrecho-Cuatro Caminos está alojada en un edificio mucho menos singular, al menos desde el exterior, y es difícilmente reconocible por los que no son musulmanes. Sirva de ejemplo el siguiente testimonio:

Yo he vivido muchos años al lado de la Mezquita de Cuatro Caminos la la que otras personas se refieren como Mezquita de Estrecho] sin saber que existía, hasta que un viernes vi a mucha gente concentrada alrededor de ella, y entonces me di cuenta.

Sin embargo otra persona me ofreció el siguiente comentario comparando ambas:

Yo la Mezquita de aquí [se refiera a la de la M-30] la encuentro muy fría [...] Es muy fría, muy fría: todo mármol. Porque yo he visto la Mezquita, la Mezquita de aquí de Cuatro Caminos [...]. Bueno pues yo la encuentro más..., más acogedora, ..., más... ¡mezquita! Esta es muy fría, yo la encuentro muy fría.

Ambas Mezquitas son lugares públicos y pueden ser visitados a cualquier hora, siguiendo unas normas determinadas. No se permite, sin embargo, hacer fotografías en el momento de la oración.

El Centro Cultural Islámico (Fig. 1) es visible desde la carretera de circunvalación de Madrid, M-30, pero se

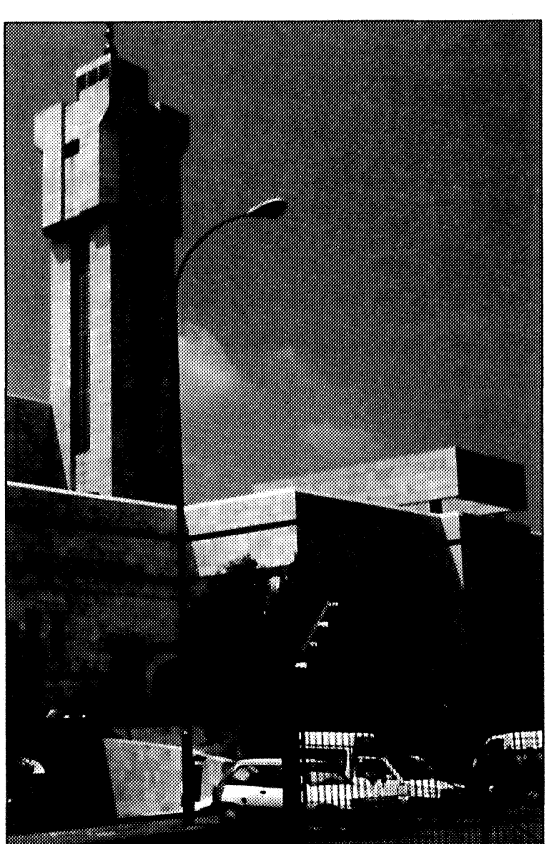

FIGURA 1.-Vista general de la Mezquita de la M-30. 
accede a él desde la calle Salvador de Madariaga; el edificio propiamente dicho está rodeado de un terreno delimitado por una alambrada que cuenta con un espacio dedicado a jardín y otro a aparcamiento de coches. Está separado del Tanatorio Municipal por un parque público, y de hecho el aparcamiento de la Mezquita puede ser utilizado por el público que visita el Tanatorio, todos los días excepto el viernes a la hora de la oración de mediodía, a cambio de una propina al vigilante.

La mezquita propiamente dicha está constituida por una sala de oración principal (Fig. 2), o sala de oración de los hombres, en la que se encuentra el Mirbab (Fig. 3) orientado hacia la Meca, que es desde donde habla el imán a toda la comunidad los viernes a medio día.

Esta sala de los hombres está emplazada en la planta baja del edificio, y cuenta con una antesala donde existen unas estanterías para dejar el calzado, y un cuarto contiguo destinado a realizar las abluciones ${ }^{9}$.

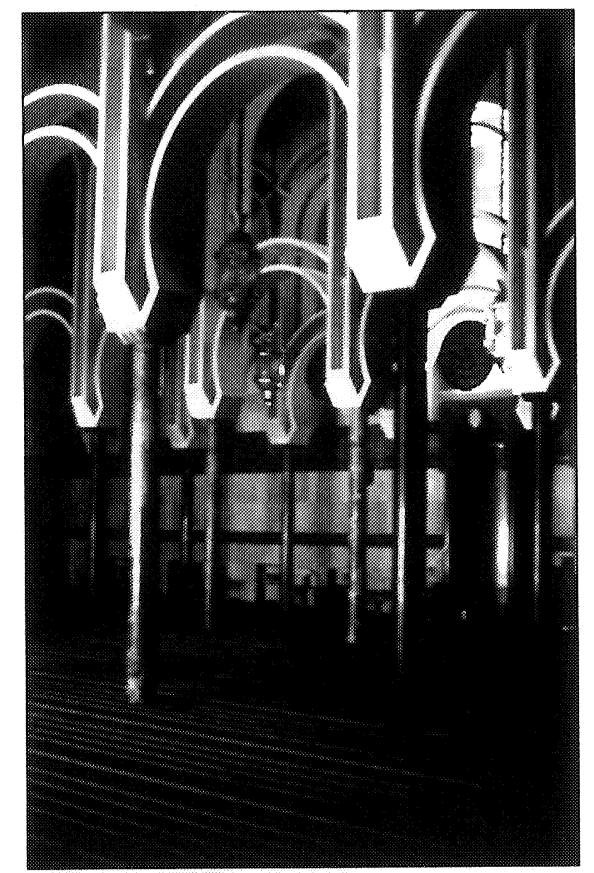

FIGURA 2.-Sala de oración de los hombres.

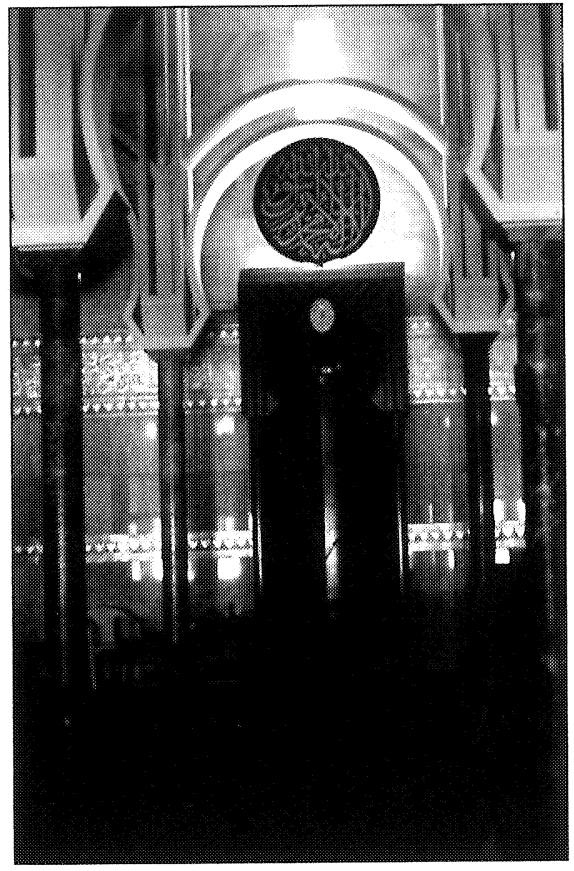

FIGURA 3.-El Mirbab en la sala de oración de los hombres.

9 El Islam prescribe que una persona debe presentarse "pura" a hacer la oración, las abluciones se realizan para conseguir este estado de pureza, y consisten en una serie de lavados (distintos si se realiza una ablución mayor o menor) de diferentes partes del cuerpo. 


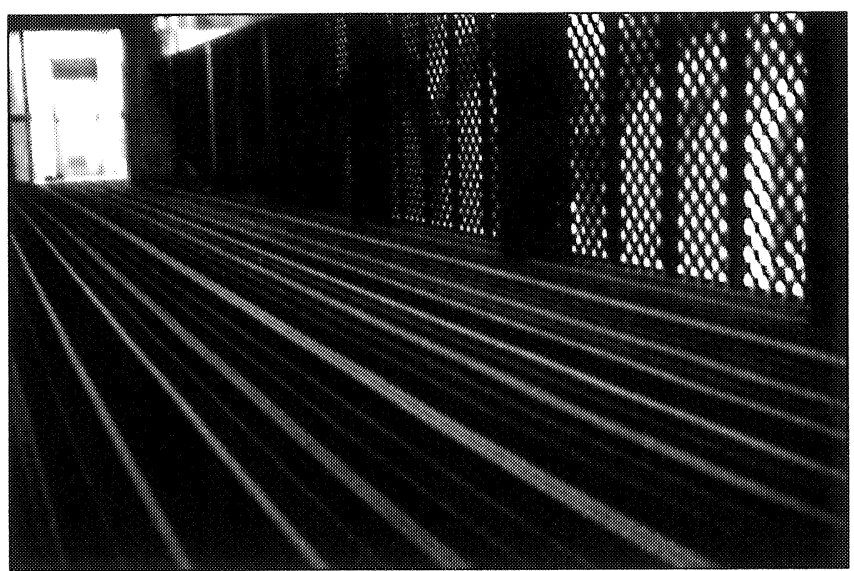

FIgURA 4.--Interior de la sala de oración de mujeres.
En el piso superior se encuentra la sala de oración de mujeres (Fig. 4). Es mucho más pequeña ${ }^{10}$. Se puede acceder a ella directamente desde el exterior del edificio a través de una "puerta de mujeres" que conecta con una escalera, pero la

entrada es visible, a través de unos cristales, a la conserjería del edificio.

Esta sala cuenta también con sus correspondientes antesala y lugar destinado a hacer las abluciones ${ }^{11}$. Tanto desde la sala como desde la antesala se puede ver y oír lo que ocurre en la sala de los hombres, a través de una celosía (Fig. 5).

Sin embargo, desde la sala de los hombres, precisamente debido

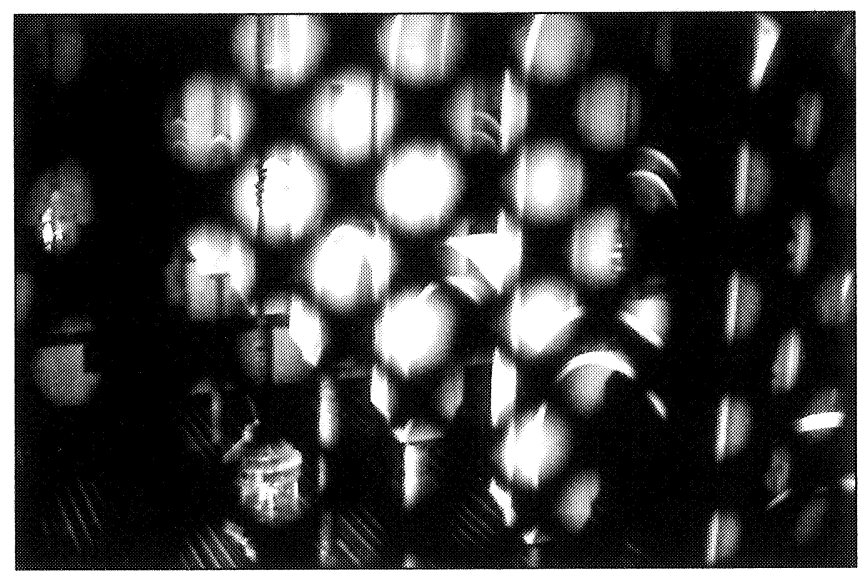

Figura 5.-La sala de oración de los hombres vista desde la sala de las mujeres.

${ }^{10}$ No es obligatorio para una mujer musulmana asistir a la mezquita, pero sí es muy recomendable para un hombre musulmán. La presencia de las mujeres en las mezquitas está regulada más por las costumbres que por las normas, de hecho se observa una gran variedad de actitudes a este respecto.

${ }^{11}$ Las abluciones prescritas para las mujeres son esencialmente las mismas que para los hombres, con una excepción: la menstruación se considera un estado aimpuro" ante el que las abluciones no tienen efecto, de manera que una mujer debe abstenerse de entrar a la sala de oración (no a la antesala) mientras está menstruando. 
a la celosía, es imposible divisar nada en la sala de las mujeres durante la oración (Fig. 6).

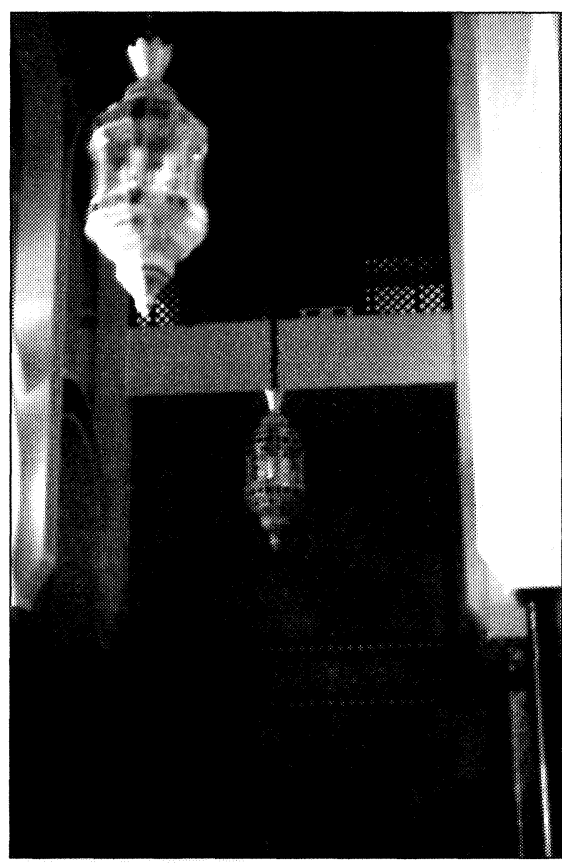

Figura 6.-La sala de oración de las mujeres, vista desde la sala de los hombres.

A partir de este recorrido gráfico por los espacios que componen la mezquita en el Centro Cultural Islámico es posible apreciar de una forma muy clara la separación de espacio por sexos, y además subrayar que el de los hombres es accesible a la vista de las mujeres, pero no viceversa. Esta norma resulta llamativa en el contexto de la ciudad de Madrid, donde por lo general no existe, como precepto, en ningún otro lugar y, como veremos más adelante al explorar otras fronteras, es uno de los marcadores simbólicos más efectivos a la hora de reconocer el espacio social musulmán en la ciudad.

Además de la mezquita, el edificio del Centro Cultural Islámico integra actualmente un colegio, en el que se imparten de forma oficial todos los grados de primaria y secundaria regulados por la legislación española, con una biblioteca, un auditorio, una sala de costura (frecuentada únicamente por mujeres), un restaurante, una sala de exposiciones, y distintas aulas destinadas a usos diversos: una clase de Corán para conversos españoles, clases de árabe, un taller de deportes, etc.

Esta asociación de usos en un edificio destinado principalmente a mezquita es un hecho singular que no responde a la tradición religiosa musulmana, por lo tanto debe ser considerada como otra estrategia adaptativa en una sociedad en la que el espacio se percibe escaso. Véase al respecto el siguiente testimonio:

Eh..., como, como no [estamos]... Por ejemplo, nosotras estamos en un país cristiano, ¿no? La Mezquita [...] La Mezquita tiene que, que tener muchos, muchos papeles, ¿no? [...] ¿Sabes? Por ejemplo la Mezquita no es solamente para rezar..., [sino también] para reunirnos con los musulmanes [...]. Si, si por ejemplo hay una fiesta..., está bien que lo celebremos en, en la Mezquita, mejor [que] en nuestras casas, ¿me entiendes?, porque..., los musulmanes siempre [se] encuentran allí, ¿me entiendes? Pero, pero, pero si estamos en nuestro país, jno! Tenemos que rezar 
en la mezquita, luego..., las fiestas [se hacen] en casa, porque todo el mundo es musulmán.

Esta combinación de lo sagrado (las salas de oración propiamente dichas) y lo profano (el taller de costura), que incluye toda una serie de usos fronterizos entre ambas categorías (las clases de Corán, por ejemplo, a las que asisten no sólo conversos sino personas interesadas en el tema que no tienen intención de convertirse, o las clases de árabe, que es la lengua sagrada del Islam, o el colegio, en el que se combina una enseñanza musulmana con el programa oficial del Ministerio de Educación español) es muy interesante y nos está demostrando dos cosas al mismo tiempo: Por un lado que la distinción entre lo sagrado y lo profano en el mundo musulmán no coincide con la que hace la sociedad española entre esos dos conceptos. Y por otro que precisamente por ello, en la negociación del espacio social está necesariamente implicada una reinterpretación de estas categorías.

Cuando he preguntado a personas no musulmanas que viven en Madrid por espacios musulmanes en la ciudad, me han remitido a varios lugares, pocas veces me han citado las mezquitas, puesto que no son muy conocidas, o al menos no resultan muy presentes. Me han subrayado "lo musulmán" de lugares como Lavapies, restaurantes donde se sirve comida al estilo de algunos países árabes, carnicerías halal, es decir carnicerías donde se vende la carne sacrificada según las normas coránicas ${ }^{12}$, y algunos mercadillos, como el que se celebra los domingos en la zona de Tetuán, o los viernes en el parque contiguo a la mezquita de la M-30 (éste último mucho menos conocido). Sin embargo, a excepción de las carnicerías, cuyo cometido es expresamente el de facilitar el cumplimiento de una norma religiosa, y de las que me han dicho:

Puedes encontrar a muchísimos musulmanes concentrados allí, hablar, charlando así, pero también comprando.

Los musulmanes con los que yo he hablado niegan rotundamente que estos espacios puedan ser considerados como "lugares musulmanes". Así me lo han expresado:

Ella: Eso no tiene nada que ver con el Islam, ¿sabes?

Yo: ¿No?, ¿no tiene nada que ver?

${ }^{12} \mathrm{El}$ animal que se va a sacrificar debe estar permitido por el Corán como adecuado para comer (por ejemplo el cerdo no lo es), lo debe sacrificar un matarife musulmán, orientado hacia la Meca, invocando el nombre de Dios, y tiene que desangrarlo completamente, puesto que no deben quedar restos de sangre en la carne que se va a consumir. 
Ella: No, no, no. Es una cosa de comercio, ¡nada más! [...] ¿Sabes?, como nosotros siempre..., por ejemplo necesitamos cosas nuestras, ¿sabes? Por ejemplo hierbabuena u...

Yo: ¡Ah!

Ella: ... Bueno, cualquier cosa, ¿no? Pero en [el] mercado español no hay, ¿sabes? $\mathrm{Y}$ como hay personas árabes que no tienen trabajo y todo, aprovechan de esta, esta ocasión y vienen [el] viernes eh..., para que..., para [vender] sus cosas. Y además hay mujeres también, y las mujeres..., así siempre hacen pan, tradicional... Yo: ¡Ah!

Ella: ... ¡Árabe! Y..., muchas cosas de dulces, de todo. Lo venden ahí en la Mezquita, pero eso no tiene nada que ver con [el] Islam. [...] A lo mejor ven..., caras marroquíes [...] ..., y dicen que es un espacio musulmán, pero no tiene nada que ver con [el] Islam. Tiene que ver con la cultura, ¿sabes? Venden cosas de..., bueno, tradicionales y todo. Pero no tiene que ver con [el] Islam, porque el Islam es una cosa y los árabes otra.

Un poco más adelante le pido que elabore un poco más estas ideas y la conversación discurrió así:

Ella: Porque árabe no significa musulmán.

Yo: ¡Claro! Y ¿qué dije...?, ¿có..., cómo se puede distinguir eso?, porque a veces es difícil.

Ella: ¿Distinguir entre árabe y musulmán?

Yo: Sí.

Ella: Porque el..., musulmán es una religión, ¿no?

Yo: Ahá.

Ella: Pero el árabe es una raza..., como cualquier raza. ¿Me entiendes? Por ejemplo un árabe puede ser judío, puede ser cristiano, como en Líbano, como en Siria. Y también puede ser budista, puede ser musulmán. Pero árabe es una raza, y ..., Islam es una religión, como cristianismo, como...

Yo: Entonces..., digamos, musulmán puede ser cualquier persona que...

Ella: Sí

Yo: ..., abracé el Islam.

Ella: Sí. Por ejemplo tú..., tú eres española: puedes ser musulmana. Una de Estados Unidos puede ser también musulmana, una de China...

Ella: Pero no puede ser árabe. ¡Arabe!, ¿sabes? Eh..., árabe no significa musulmán. Yo: Ahá. Para ser árabe...

Ella: ¡Y musulmán no significa árabe!

Yo: Para ser árabe...

Ella: Tiene que pertenecer a una raza que sea ma...

Yo: Pero ¿y cómo pertenezco? O sea..., ¿el hijo de quién es árabe? El hijo de un padre árabe y una madre que no sea árabe, ¿es árabe?

Ella: Sí.

Yo: ¿Y el hijo de un padre...?, ¿de una madre que sea árabe y un padre que no sea árabe...?

Ella: ¡No!

Yo: $O$ sea es por línea del padre.

Ella: ¡Eso es! 
Yo: Ahá.

Ella: Porque..., el niño luego va a llevar su..., el apellido de su padre...

Yo: Ahá.

Ella: ..., y el apellido de su padre es árabe, ¿no?

Yo: Ahá.

La mayoría de los no musulmanes en Madrid, por el contrario, emplean las palabras árabe y musulmán prácticamente como sinónimos, por eso cuando yo hablo de la existencia de un grupo de españoles que se han convertido al Islam suelo provocar, primero, una gran sorpresa en mis interlocutores, y después, la necesidad de una explicación. La que con más frecuencia me ofrecen como plausible es el matrimonio, lo que supone, de nuevo, una necesidad de identificar la religión (musulmana) con la afiliación (árabe), en este caso en favor de una posible futura descendencia. Sin embargo, según el derecho islámico un hombre musulmán puede contraer matrimonio con una mujer de religión cristiana o judía sin que sea necesaria su conversión al Islam. El caso contrario no es posible: a una mujer musulmana sólo le está permitido casarse con un hombre musulmán, de manera que éste sí es un motivo para la conversión, a veces puramente nominal.

La conversión de una mujer es, por lo tanto desde el punto de vista legal, un acto voluntario, y por este motivo, desafía la identificación de las categorías árabe/musulmán y plantea siempre un problema de comprensión entre las personas que no pertenecen al Islam. Este desafío es muy importante, en primer lugar porque plantea problemas a la hora de conceptualizar tanto la reinterpretación de nuestro pasado histórico, como nuestra categorización presente de la relación entre el mundo musulmán y el mundo occidental, y en segundo lugar porque una mujer musulmana tiene pocas posibilidades de maniobrar ante la frontera simbólica que distingue entre los musulmanes y los que no lo son, de manera que su conversión se convierte en un desafío particularmente visible.

El Corán exige textualmente que los hombres y las mujeres vistan con modestia, pero la mayoría de los musulmanes, hombres y mujeres, interpretan que a las mujeres musulmanas sólo les está permitido mostrar su cara, sus manos y sus pies delante de los hombres que no pertenecen a su familia. A la hora de seguir esta norma, sólo se distinguen, a simple vista, en la sociedad madrileña por cubrirse completamente el pelo, tanto en lugares públicos como privados, y de la misma manera en espacios cerrados que abiertos. De esta manera el "velo" se convierte en un "marcador" simbólico físico y fácilmente reconocible, y es por este motivo por el que he afirmado que las mujeres musulmanas tienen pocas posibilidades a la hora de manipular las fronteras que las adscriben a su grupo en 
el contexto de la sociedad madrileña. El momento más crucial para una conversa es aquel en el que decide adoptar el velo en público, porque de esta forma hace visible una decisión privada, y a partir de ese momento su condición de musulmana y española (o no árabe) comienza a plantear un desafío público. Muchas de mis informantes han empezado a tener serios problemas con sus familias precisamente en ese momento, desencadenando, en varias ocasiones, una ruptura total de las relaciones.

Ahora bien, debo subrayar que muchas de ellas me han aclarado expresamente que estas dificultades las perciben como una prueba de Dios a su conversión, por ejemplo en el caso de una conversa a quien su familia se negó a ver, a pesar de la insistencia de ella, hasta que nació su segundo hijo. Por su parte, la madre de un converso varón, cuando le pregunté sobre la conversión de su hijo me dijo:

Hombre ..., en principio a nosotros nos dio un ..., casi un "Sopipapo", porque ya te puedes imaginar, que te llegue un hijo y que te diga: ¡Me convierto! Pero bueno, ¿qué hemos hecho nosotros para merecer esto? Pero luego como ves que es muy bueno ....

Me gustaría subrayar la expresión "ya te puedes imaginar", porque supone que su actitud sería la de cualquier otra persona, incluida la mía; de esta manera no está expresando una situación personal, sino una reacción lógica, adecuada a las normas que compartimos todos.

El precepto de cubrirse el pelo no sólo es un requerimiento para las mujeres musulmanas, sino para cualquier mujer, que quiera entrar en un espacio sagrado, a este efecto existen en la mezquita unas capas a disposición de las visitantes que no vayan vestidas de forma adecuada, en tanto que el atuendo corriente de los hombres madrileños no presenta ningún problema.

\section{LAS ALTERNATIVAS SOCIALES QUE GENERAN LAS DIFERENCIAS}

El mundo musulmán en Madrid ha generado una serie de espacios sociales en la ciudad que son percibidos de forma distinta por los musulmanes y por los que no lo son. En términos generales, el material analizado me permite afirmar ${ }^{13}$ que para unos resulta insuficiente, mientras que los otros lo perciben como asociado a lo extranjero o a la inmigración.

\footnotetext{
${ }^{13}$ Aunque, como he advertido al principio, se trata de un trabajo en curso y por lo tanto cualquier conclusión tiene la intención de ofrecer ideas para un debate.
} 
Se ha podido apreciar, a través de algunos ejemplos, cómo los musulmanes suplen la escasez de su espacio social manipulando las fronteras entre lo público y lo privado, empleando para ello dos estrategias fundamentales: por un lado, la tendencia a compartir el espacio privado para celebrar actos públicos, y por otro ampliando los usos del espacio público, trasladando algunas de las actividades que tradicionalmente correspondían al ámbito de lo privado (como pueden ser las fiestas o los ritos que acompañan a determinados momentos significativos de la vida de una persona: el nacimiento, la mayoría de edad, la formación de una familia o la muerte) a la esfera pública.

Los no musulmanes son poco conscientes de la existencia del espacio social "musulmán" en Madrid, y cuando lo son lo identifican automáticamente con lo árabe, de manera que tienden a "extranjerizarlo", si se me permite la expresión. Esta afirmación resulta evidente cuando expresan dificultades para entender las conversiones al Islam que se producen de forma voluntaria entre algunos españoles, muchos de los cuales, especialmente cuando se trata de mujeres cuya elección se hace "visible" a los ojos de los demás, ven dificultadas sus relaciones sociales anteriores a la conversión.

Entre ambas percepciones, y a pesar de las distorsiones, se está produciendo una negociación social que está permitiendo que el Islam sea una religión que, hoy por hoy, pueda practicarse en Madrid, quizá aún de manera precaria e insuficiente, $y$, desde luego, después de un esfuerzo de adaptación innegable.

Ahora bien, otra cuestión diferente es tratar de responder a la pregunta inicial de si esta estructura social nueva resulta accesible a la población en general, y si supone un enriquecimiento de las alternativas sociales de los ciudadanos a la hora de decidirse por un estilo de vida diferente. O dicho de otra manera, si la existencia de un grupo de musulmanes en la ciudad contribuye a movilizar procesos sociales relacionados con la "globalidad", entendida desde lo que hoy día se define como "modernidad".

La respuesta es compleja, porque los procesos implicados también lo son. Por un lado, es cierto que algunos madrileños han percibido el Islam como una alternativa a su estilo de vida anterior y de hecho lo han adoptado. Es innegable, en este sentido la existencia de un grupo de conversos, pero por otro, hay que reconocer que estamos hablando de casos muy puntuales, cuyas biografías demuestran que es una posibilidad derivada de avatares personales muy concretos, es decir se trata más bien de una alternativa circunstancial que estructural.

Es evidente que el tiempo tiene mucho que ver con todo ello, ya que se trata de un fenómeno nuevo. La mayor parte de las personas que hoy 
integran en Madrid la comunidad musulmana son inmigrantes extranjeros, y la inmigración en España en general y en Madrid en particular es un fenómeno reciente, que data de principios de la década de los 80 , fundamentalmente. Pero además del tiempo, este trabajo ha pretendido revelar otros elementos que deben ser tomados también en cuenta, y resultan particularmente sobresalientes al considerar las fronteras.

Las fronteras simbólicas se generan en el proceso de contacto, y especialmente de lo que "choca" en ese contacto. Hay muchas diferencias que no funcionan como fronteras simbólicas, precisamente porque no producen ese "choque", de manera que no entran en consideración cuando se trata de delimitar. Hay otras diferencias que no sólo son distintas, sino contrarias. Esto quiere decir que las diferencias son significativas cuando se trata de normas de comportamiento contradictorias. Con esas contradicciones elaboramos los límites que utilizamos para "marcar" o identificar ${ }^{14}$ de manera simbólica.

En el caso del espacio musulmán en la ciudad de Madrid, y analizando el material utilizado, esos marcadores derivados del contraste han resultado ser dos: la norma de separación de sexos en el espacio público, por un lado, y la obligación de las mujeres de llevar el "velo" para cubrirse el pelo en presencia de los hombres, por otro. El primero de ellos es más abstracto y menos visible, por lo tanto es más efectivo el segundo.

$\mathrm{Ni}$ lo uno ni lo otro, como costumbre, resulta extraño en el resto de la sociedad madrileña, donde las mujeres se han cubierto la cabeza por tradición, al menos durante mi infancia ${ }^{15}$, y donde tampoco suele ser infrecuente, en una reunión familiar o amistosa, observar a los hombres charlando con los hombres y a las mujeres en un corrillo de mujeres ${ }^{16}$. El problema es la norma, el tener que hacerlo de manera involuntaria e impuesta, y no de forma aparentemente espontánea. La norma resulta vejatoria por "retrógrada" $\mathrm{y}$ "machista". $\mathrm{Y}$ este sentimiento es una manera de reaccionar ante una sociedad patriarcal que admitimos sólo como una

${ }^{14}$ Esta argumentación la desarrollé por extenso en del Olmo (1990).

${ }^{15}$ En una de las visitas que he hecho a la mezquita de la M-30 en Madrid me acompañaron mi madre y mi tía. A ambas les advertí de la norma de cubrirse la cabeza, y por lo tanto las dos llegaron, como yo, provistas de su propio pañuelo de cabeza. Cuando se lo colocaron evocaron inmediatamente en mi cabeza una imagen familiar, ya que las había visto vestidas así muchas veces, quizá con los mismos pañuelos que rescataron del fondo de un armario.

${ }^{16}$ De la misma forma, cuando se reúnen dos parejas para compartir un mismo coche, he observado muchas veces ofrecer el asiento contiguo al conductor a la persona del mismo sexo que está conduciendo, especialmente si el que conduce es un hombre. 
rémora del pasado, y por lo tanto opuesta a lo que consideramos que significa la modernidad.

Aceptar ambas normas entraña por lo tanto una peligrosa asociación con el pasado, y este es el verdadero problema; por ello son estas diferencias y no otras las que constituyen los límites, y por eso estos límites son difíciles de cruzar.

El grupo de conversos españoles al Islam debería funcionar como un puente que conectara los dos ámbitos, como traductores de diferencias, pero, hoy por hoy, no lo hacen. Y no lo hacen porque de momento no pueden. Su opción de estilo de vida no se considera algo "plausible", sino una anomalía, y se buscan explicaciones anómalas para su comportamiento. Su elección es vista en el mejor de los casos como un comportamiento "extranjero", en el peor, como una vuelta a lo peor del pasado, a un pasado que parece que hemos juzgado y censurado pensando que estábamos todos de acuerdo, y por lo tanto no permitimos que nadie venga con su comportamiento a arrancarnos ese acuerdo, tan penosamente conseguido, y mucho menos a dudar de él. Una mujer con un velo supone un desafío a esa convicción de modernidad, por este motivo desencadena de manera tan fácil y tan automática la polémica.

Sólo veo posible trascender este antagonismo adoptando otra idea de modernidad. Una idea como la que se ha desarrollado aquí citando la obra de Appadurai (1995 y 1999) y que consiste en aceptar más posibilidades, más alternativas, en considerar que las diferencias son una fuente de riqueza y de futuro.

\section{BIBLIOGRAFÍA CITADA}

AmÉrigo Cuervo-ARANGo, FERnANDo. 1995. "Breve apunte histórico de la relación estado-confesiones religiosas en España", en M. Abumalham (ed.), Comunidades islámicas en Europa: 165-172. Madrid: Trotta.

APPADURAI, ARJUN. 1995. "Global Ethnoscapes: Notes and Queries for a Transnational Anthropology", en R.G. Fox (ed.), Recapturing Anthropology: 197-210. Santa Fe, Nuevo Mexico: School of American Research Press.

- 1999. Modernity at Large. Cultural Dimensions of Globalization. Minneapolis, Minnesota: University of Minnesota Press.

García-Arenal, Mercedes. 2000. "El Islam en la Península Ibérica y la memoria histórica de España". Fulcro 16: IX-XIII.

IzQUIERDO, ANTONIO. 1992. La inmigración en España, 1980-1990. Madrid: Ministerio de Trabajo y Seguridad Social.

- 1996. La inmigración inesperada: la población extranjera en España (1991-1995). Madrid: Trotta. 
MANZANO, EDUARDO. 2000. "La construcción histórica del pasado nacional", en J.S. Pérez Garzón (ed.), La gestión de la memoria La historia de España al servicio del poder. 33-62. Barcelona: Crítica.

Del Olmo, Margarita. 1990. La construcción cultural de la identidad: inmigrantes argentinos en España. Madrid: Universidad Complutense.

Del Olmo, MARgarita y Mónica QUijada. 1992. "Los movimientos migratorios como procesos de desorganización y reorganización cultural. Antropología 2: 145-149.

TATRY BAKRY, RIAY. 1995. "Libertad religiosa y acuerdo de cooperación del estado español con la Comisión islámica de España", en M. Abumalham (ed.), Comunidades islámicas en Europa: 165-172. Madrid: Trotta. 